\title{
Study on the Application of CVP Analysis in Catering Industry
}

\author{
Yan Jiang \\ Jiangsu University of Science and Technology \\ Zhenjiang, China
}

\author{
Zhirong Shen \\ Jiangsu University of Science and Technology \\ Zhenjiang, China
}

\begin{abstract}
Cost-Volume-Profit (CVP) Analysis method is an effective method for the forecasting of cost, realization of target profit and decision analysis of a company. At present, the CVP analysis method is mainly used in the manufacturing industry, yet it is rarely used in the catering industry. This paper conducts case study taking a restaurant as an example. First of all, it analyzes the restaurant's cost nature, and then the breakeven analysis, the analysis of safe operation degree, the analysis of influence on restaurant profit changes by factor changes. This paper provides the restaurant manager with better operating decision by positioning analysis of multi-element within the catering industry, and surveying the relationship among the major elements of catering industry as well as the impact caused by element changes.
\end{abstract}

Keywords—restaurant; breakeven; sensitivity analysis

\section{INTRODUCTION}

In recent years, the catering industry's income growth gradually slows down by the impact from slowing growth of domestic and foreign economy, food safety issues and other uncertain factors. Most companies are facing the problems such as the rising food raw material cost, rising labor costs, rising rents, lack of management talents and other issues. [1] Moreover, the profit growth in catering industry is also inhibited by the "three public" consumption reduction, the promotion of implementing frugal food consumption in the market as well as other policies and human factors. As a result, the catering industry is gradually entering into the "small profit period". Catering industry involves many aspects in menu plan, food and beverage control, food and beverage marketing and cost accounting, resulting in quite a lot of cost leakage points in its business activities. As a result, the accounting and analysis of catering cost is even more important. Restaurant managers can predicate and analyze restaurant operation as well as determine the critical amount of profit and loss by virtue of CVP analysis method as it is an effective analytical method in management accounting. Thereby, they are able to control restaurant cost, business volume and profits effectively, and provide basis for their operating and decision-making through setting some quantitative assessment indicators.

\section{OVERVIEW OF CVP ANALYSIS AND ITS APPLICATION IN CATERING INDUSTRY}

\section{A. Meaning of CVP Analysis}

CVP analysis is the abbreviation of analysis of relationship among cost, volume and profit, referring to reveal the internal regular relation of fixed cost, variable cost, sales volume, unit price, sales, profit and other factors using mathematical accounting model and graphics based on variable cost calculation mode. The basic formula of CVP analysis is: Profit $=$ Sales Volume $\times$ Unit Price - Variable Cost - Fixed Cost. [2]

The application of CVP analysis method into catering industry enables the catering industry managers to predict and control the cost, sales, sales volume, number of customers, profit and other factors, and to understand the changes caused by the mutual influence and dependency among different factors, as well as the impact on corporate profits. The effective application of CVP analysis method provides a good reference platform for the catering industry managers, for example, if a company wants to adjust the cuisine, yet the new cuisine has higher labor costs and raw material prices, then how about the fluctuations of breakeven point; how to define the company's price system with the new breakeven point; how the customer quantity and breakeven point will fluctuate under the new cuisine and price system and so on. The CVP analysis of catering industry is the product of the manager's experience and scientific calculation, which fully reflects the mutual cooperation of experience and quantitative management, and helps the restaurant manager in judging and making decisions about the future business.

\section{B. Cost Behavior Analysis of Catering Enterprises}

To conduct CVP analysis, first of all, the restaurant's business volume shall be defined and cost behavior shall be divided. The business volume of restaurant is the indicator of its business activity level. The division of restaurant's business volume can be very flexible, which can be the processing quantity or sales volume of the dishes, or the number of people dining, the restaurant attendance and so on. Catering cost refers to sum of various costs and expenses incurred by the restaurant in the course of producing and supplying food and beverage products, that is, the monetary expression of the materialized labor and other labor activities consumed by enterprises in production and operation process. Specifically, the costs include raw material consumption, staff salaries, 
utilities, fuel costs, and consumption of materials, low-value consumables amortization, rental costs, and depreciation of fixed assets, office expenses, advertising expense, maintenance costs and other expenses and so on. According to the dependency relation of various costs and business volume, the cost of restaurants can be divided into the following three categories:

1) Fixed cost: refers to the cost that will not change along with the increase or decrease of business volume. Fixed costs of restaurant generally include the rent, staff fixed wages, depreciation of facilities, fees of low-value consumables amortization, office expenses and so on. If the restaurant pays advertising, publicity and other promotional costs to specific media monthly, the cost is also fixed cost. That refers to the expense the restaurant has to pay regardless of business conditions. Uncontrollable cost of restaurant generally refers to the fixed costs, but some fixed costs still have certain controllability, such as advertising costs, restaurant renovation costs, etc., which can be reduced appropriately when the enterprise operating funds is insufficient

2)Variable cost: refers to the cost whose total amount changes direct proportionality along with changes in business volume. The cost of restaurant's food raw materials and the performance-related chef's wage cost is the typical variable cost. Restaurant's food raw material expense and beverage cost will increase with the increase of people dining in the restaurant. Generally, variable cost is controlled costs, for restaurant can change the manufacturing cost by changing weight or ingredients of the dishes, or to control labor cost by increasing or decreasing the waiters or waitresses. In theory, if the dish is not sold, the restaurant's variable cost can be regarded as zero.

3) Mixed cost: refers to the cost includes both the variable cost and fixed cost. Take the electricity cost of enterprise kitchen as an example. The refrigeration equipments in kitchen have to be in normal running state regardless of the number of customers; the electricity consumption of electric oven, electric baking pan and other equipment changes along with the increase or decrease in production. However, the powerconsuming items cannot be separated when calculating electricity consumption. As a result, the electricity cost is mixed cost.

To divide the cost according to cost behavior is mainly to provide theoretical basis for the way of cost control and analysis of profit and loss. Generally, the top management gives priority to fixed cost control; low and middle level management gives priority to variable cost and controllable cost control, thus to reduce the cost as much as possible. [3] The analysis via cost behavior of CVP enables the manager to manage and control restaurant cost in a better way, and thereby improving the restaurant's economic benefit.

\section{SPECIFIC APPLICATION OF CVP ANALYSIS IN CATERING INDUSTRY}

In order to clarify the specific application of CVP analysis in catering industry, this paper explains by taking a restaurant as an example. $\mathrm{X}$ restaurant is a franchise, with franchise fee of 300,000 yuan, deposit of 150,000 yuan and management fee of
150,000 yuan. There is no need for restaurant to include deposit into profit or loss as it will be refunded upon expiration of the contract according to regulations. The renovation cost of this restaurant is 300,000 yuan, and the equipment fee is 450,000 yuan (5-year depreciation period). The office expenses, wages, travelling expenses and other start-up cost incurred by the restaurant are 90,000 yuan. The franchise fee and start-up cost are calculated by 5-year depreciation period. After opening, the monthly rent of 60,000 yuan, utilities of 30,000 yuan, and staff fixed wages of 58,500 yuan will be incurred by the restaurant and shall be paid monthly. The average selling price of each dish is 45 yuan, and average cost is 15 yuan.

\section{A. Analysis of the Application of Enterprise Break-even Point}

The break-even point analysis is an essential part of CVP analysis, which mainly studies how to determine the breakeven point, the impact on break-even point by changes in relevant factors and other issues, so as to provide managers with decision information, such as with which business volume the restaurant will gain profits, and with which business volume the restaurant will loss. [4]

The restaurant's break-even point is the state point of profit and loss balance in its operation. The balance of restaurant's product cost after deducting its variable cost is called marginal contribution. If the marginal contribution after deduction of all fixed costs remains a certain balance, the restaurant will gain profit. Otherwise, the loss will be incurred. When the marginal contribution just makes up for all the fixed costs, the sales volume at this time is the break-even point, and the formula is Break-even Point $=$ Total Fixed Cost - (Unit Price - Unit Variable Cost).

The restaurant's monthly fixed cost is summarized according to above information and the total monthly fixed cost of 180,000 yuan is obtained. Summary calculation process is shown in "Table I".

TABLE I. SUMmary SHEET OF X RESTAURANT'S TOTAL MONTHLY FIXED COST ( UNIT: YUAN)

\begin{tabular}{|l|l|l|}
\hline & $\begin{array}{l}\text { Franchise fee and start - up fee } \\
\text { amortization }\end{array}$ & 6500 \\
\cline { 2 - 3 } & Management fee amortization & 12500 \\
\cline { 2 - 3 } & $\begin{array}{l}\text { Depreciation of equipment and decoration } \\
\text { costs }\end{array}$ & 12500 \\
\cline { 2 - 3 } & Rent & 60000 \\
\cline { 2 - 3 } & Utilities & 30000 \\
\cline { 2 - 3 } & Staff fixed wages & 58500 \\
\hline Total & & 180000 \\
\hline
\end{tabular}

a) Breakeven point with dish sales volume as the business volume: If X restaurant's cost of dishes is regarded as the only variable cost, the average variable cost is 15 yuan, then the dishes' monthly sales volume at breakeven point $=$ monthly fixed cost / (dish unit price - average cost of dishes $)=$ $180000 / 15)=6000$ (pieces). That is, when the restaurant's 
monthly sales volume of dishes reaches 6,000 pieces, only the breakeven cost is incurred by it.

b)Breakeven point with number of customers as the business volume: After one month trail operation, it is found that the increase in amount of expenses accounts for about $60 \%$ of the sales. The minimum unit consumption price is 70 yuan. Here, it is assumed that the cost that changes along with the number of consumers of $X$ restaurant is 40 yuan. Calculation of $\mathrm{X}$ restaurant's monthly customer quantity at the breakeven point $=$ fixed cost $/$ (unit consumption price unit variable cost $)=180000 /(70-40)=6000$ (person). That is, when the monthly consumer quantity of this restaurant reaches 6000 person, the breakeven cost is incurred by this restaurant.

c)Breakeven point when there is a discount: If the investor of this restaurant do not want to join the original restaurant brand, but the popularity of this restaurant or a certain cuisine is needed to be improved, then this restaurant can participate in the online group purchase activities, because the nature of the organization of group purchase is also a kind of advertising. At this time, the CVP analysis can also be used for determining the breakeven point when discount exists in the restaurant.

It is assumed that the effect of group purchase is equivalent to the effect of investing in franchise fee as before. As for the previous franchise fee, if calculated as per the original average price of certain cuisine of 45 yuan per dish, the monthly sales are 7,000 dishes, the monthly fixed cost is 180,000 yuan, variable cost is 10 yuan per dish, and the dish price of group purchase is 40 yuan. As the restaurant will pay commission to group-purchase website, so the variable cost of the dish is 13 yuan if it is bought by group purchase, and the monthly sales are 7,000 dishes. Therefore, the CVP formula of a group purchase is: Profit after group purchase $=$ dish price after group purchase $\times$ sales volume after group purchase - variable cost of the dish after group purchase $\times$ sales volume after group purchase - fixed costs

If the invested franchise fee of 5,000 yuan (by monthly conversion) is regarded as the maximum amplitude of loss, then the minimum dish price the restaurant can bear = (previous monthly franchise fee + monthly fixed cost + variable fee after group purchase $\times$ sales volume after group purchase $) /$ sales volume after group purchase $=(5000$ $+180000+13 \times 7000) / 7000=39.42$ (yuan)

Then, the minimum discount rate at the time of group purchase $=39.42 / 45=78.86 \%$

As a result, the so long as the restaurant's group purchase discount is higher than $21 \%$, it can be considered reasonable.

\section{2) Calculation of dynamic breakeven point}

We assume that the unit price, fixed costs, unit variable cost and many other factors do not change while calculating the breakeven point. However, such static balance cannot be maintained for long actually, as these factors are often changing. Therefore, it is necessary to calculate the impact on breakeven point by the changed consumption standard, unit variable costs and total fixed costs. a) Impact on Breakeven Point by Changed Consumption Standard: The impact of changed customer consumption standard on breakeven point can be illustrated directly by the breakeven point graph as shown in Figure 1. In Figure 1 of breakeven point, based on a certain level of cost, the higher the customer consumption standard and the greater the slope of restaurant's total income line, the lower the breakeven point will be. In this way, the profits gained with same quantity of consumers will be higher or the loss will be fewer. [5] If the customer consumption standard is increased to 80 yuan per person, then the monthly consumer flow at breakeven point $=180000 /(80-40)=4500$ (person), 1500 person fewer compared to the previous consumption standard of 70 yuan. Therefore, under the condition that other factors remain unchanged, if the restaurant increases customer consumption standard, it can effectively improve the marginal contribution, so as to reduce the breakeven point and gain more profits with same quantity of consumers. But it is worth noting that consumption standard improvement may also bring about the negative impact of market share decline. Therefore, a comprehensive analysis from various aspects shall be conducted in order to make the decision in favor of restaurant business. "Fig. 1"

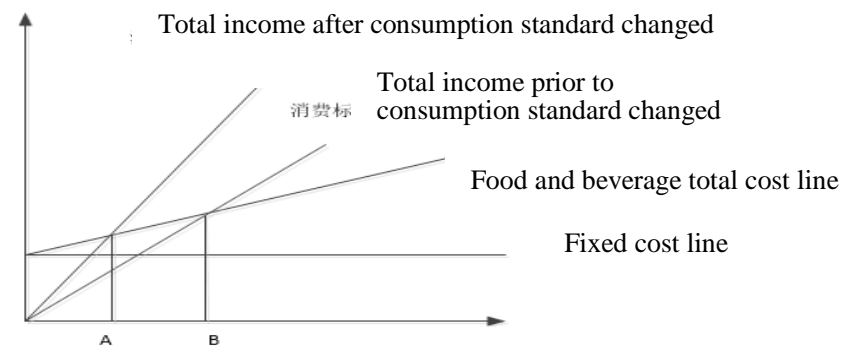

Fig. 1. Diagram of Breakeven Point after Consumer Consumption Unit Price Changed.

b) Impact on breakeven point by changed variable cost: The breakeven graph of impact on breakeven point by changed variable cost is shown in "Fig. 2". In "Fig. 2", the changing direction of breakeven point coincides with the direction of unit variable cost with other factors remain unchanged. When the unit variable cost increases, the unit contribution gross profit decreases correspondingly as per its additional amount, and the breakeven point increases. The greater the variable cost, the greater the slope of the variable cost line, the higher the breakeven point will be, and the profits gained with same consumer flow will fewer or the loss will be greater. If the variable cost of this restaurant is increased to 45 yuan per person, the monthly consumer flow at breakeven point $=180000 /(70-45)=7200$ (person). Therefore, the restaurant shall control the typical variable costs, such as cost of food raw materials. Procurement, acceptance, storage, production and other aspects of food raw materials will have a great impact on the restaurant's variable cost, generating fluctuations in breakeven point. 


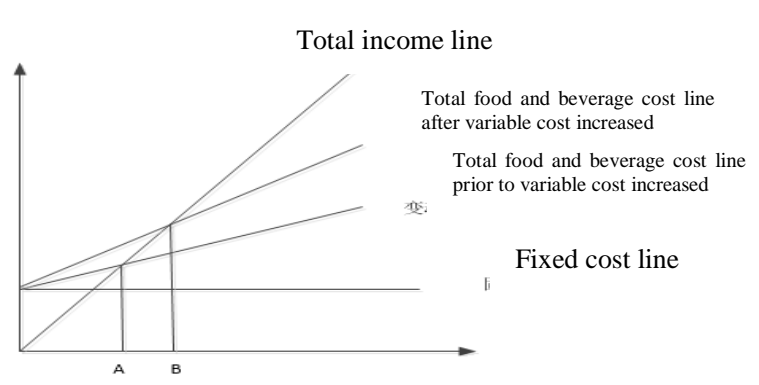

Fig. 2. Diagram of Breakeven Point after Variable Cost Changed.

c) Impact on breakeven point by changed fixed cost: In the diagram, the total sales line moves up due increase of fixed cost, making the breakeven point be increased and the profits be reduced correspondingly. If other factors remain unchanged, but the monthly fixed cost increased to 190000 yuan, then the monthly consumer flow at breakeven point = $190000 /(70-40)=6334$ (person), which can be described with Figure 3 . When the fixed cost increases, the breakeven point will also increase if other factors remain unchanged. Therefore, the restaurant shall weigh the influence of consumer flow changes brought by fixed cost and the overall changes in profits when it plans to increase kitchen equipment or the advertising costs and other fixed costs. "Fig. 3"

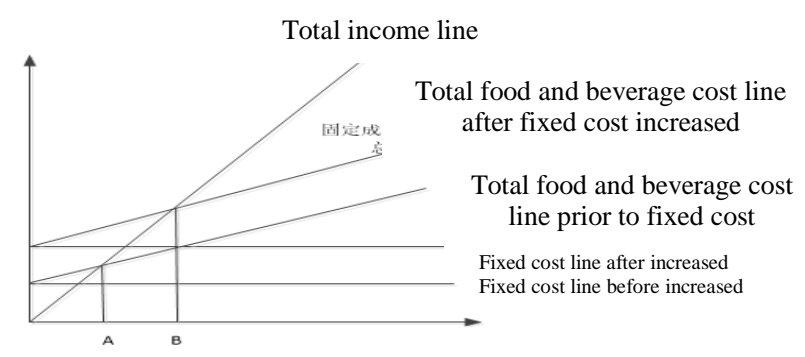

Fig. 3. Diagram of Breakeven Point after Fixed Cost Changed.

The above analysis is against the impact on breakeven point by single factor changes. However, in the actual work, the factors are not isolated but influence each other. Therefore, the restaurant shall grasp the objective reality, and calculate the impact brought by the changes in various relevant factors at the same time. If the influential factors change simultaneously, then the total cost line and income line will move simultaneously, which will definitely lead to changes in breakeven point. The direction and distance of breakeven point movement as well as the profit amount will be determined by the combined effect of these factors.

3) Determination of critical value of change of related factors

In the CVP analysis, the amount of change making a restaurant turn from profit to loss refers to the critical value of relevant variables. Mastering the loss critical value of a restaurant will enable the restaurant to adjust its operation decision, to avoid loss or minimize the loss.
For example, the total monthly fixed cost of $\mathrm{X}$ restaurant is 180,000 yuan, the minimum consumption fee is 70 yuan/person, the single variable cost that changes along with consumer flow is 40 yuan, and the consumer quantity at breakeven point is 6000 . Assume the monthly consumer flow is 6400 , then its:

(1) Maximum allowable value of unit variable cost $=(6400$ $\times 70-180000) / 6400=41.88$ (yuan), namely, when unit variable cost exceeds 41.88 yuan, it is bound to loss.

(2) Maximum allowable value of fixed cost $=6400 \times(70$ 40) $=192000$ (yuan), namely, when the fixed cost exceeds 192,000 yuan, it is bound to loss.

(3) Minimum allowable value of monthly number of customers $=180000 /(70-40)=6000$ (person), namely, when the number of customers is below 6,000 people, it is bound to loss.

(4) Minimum allowable value of consumer consumption standard $=(6400 \times 40+180000) / 6400=68.125$ (yuan), namely, when the customer consumption standard is less than 68.125 yuan, it is bound to loss.

It can be seen from the calculation of breakeven point that consumption standard, fixed cost, changes in costs and other factors will have an impact on the breakeven point. Therefore, if the impact on breakeven point can be known in advance, certain measures can be taken to reduce the breakeven point. Therefore, restaurant's loss will be avoided or reduced.

\section{B. Analysis of Business Operation Security}

The enterprise shall also consider the security degree of business operation in addition to control of breakeven point situation. The commonly used indicators to measure business operation security include safe marginal amount and rate of safety margin. Among them, the safe marginal amount = actual sales volume - sales volume at breakeven point; rate of safety margin $=$ safe marginal amount $\div$ actual sales volume. The value of actual consumer amount exceeding the consumer amount at breakeven point is the "safe margin" of a restaurant. Because only when the more the normal consumer quantity exceeds the consumer quantity at breakeven point, the more profit the restaurant will gain; otherwise, the smaller the profits will be. From the perspective of restaurant business operation, the larger the difference between normal consumer flow and consumer flow at breakeven point, the more the final profit formed by contribution margin provided by the exceeding part, the more safe the restaurant operation will be; vice versa. The test standards for business operation safety are shown in "Table II" below.

TABLE II. TABLE OF SAFETY INSPECTION STANDARD

\begin{tabular}{|c|l|l|l|l|l|}
\hline $\begin{array}{c}\text { Rate of Safety } \\
\text { Margin }\end{array}$ & Below 10\% & $10 \%-20 \%$ & $20 \%-30 \%$ & $30 \%-40 \%$ & $\begin{array}{l}\text { More than } \\
40 \%\end{array}$ \\
\hline $\begin{array}{c}\text { Degree of } \\
\text { Safety }\end{array}$ & Dangerous & $\begin{array}{l}\text { Worthy of } \\
\text { Note }\end{array}$ & $\begin{array}{l}\text { Relatively } \\
\text { Safe }\end{array}$ & Safe & Very Safe \\
\hline
\end{tabular}

Take the abovementioned $\mathrm{X}$ restaurant as an example. 80 seats in total are set in this restaurant, and the attendance and repeated utilization of tables are calculated after three-month business, with the specific data shown in "Table III". 
TABLE III. ATtENDANCE AND REPEATED UTILIZATION OF TABLES OF X RESTAURANT

\begin{tabular}{|c|c|c|c|c|c|c|c|c|c|c|c|c|c|c|c|c|}
\hline & \multicolumn{5}{|c|}{ Lunch (11a.m. - 1 p.m.) (person) } & \multicolumn{5}{|c|}{$\begin{array}{c}\text { Dinner (6 a.m. - } 9 \text { p.m.) } \\
\text { (person) }\end{array}$} & \multicolumn{5}{|c|}{ Other Periods (person) } & \multirow[b]{2}{*}{ Total } \\
\hline & 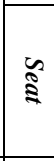 & 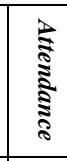 & 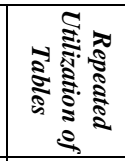 & 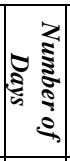 & 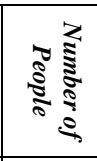 & $\stackrel{\S}{\S}$ & 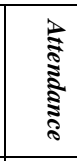 & 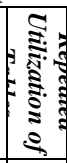 & 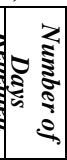 & 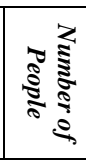 & 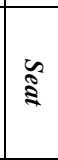 & 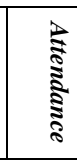 & 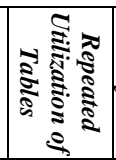 & 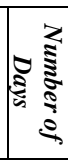 & 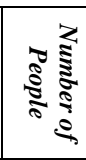 & \\
\hline $\begin{array}{l}\text { Mon. to } \\
\text { Thu. }\end{array}$ & 80 & 0.7 & 1 & 4 & 224 & 80 & 0.75 & 1.8 & 4 & 432 & 80 & 0.6 & 0.5 & 4 & 96 & 752 \\
\hline Fri. & 80 & 0.8 & 1 & 1 & 64 & 80 & 0.85 & 2.5 & 1 & 170 & 80 & 0.7 & 0.5 & 1 & 28 & 262 \\
\hline Sat. & 80 & 0.85 & 1.5 & 1 & 102 & 80 & 0.85 & 2.5 & 1 & 170 & 80 & 0.7 & 0.5 & 1 & 28 & 300 \\
\hline Sun. & 80 & 0.85 & 2 & 1 & 136 & 80 & 0.8 & 2.5 & 1 & 160 & 80 & 0.75 & 0.7 & 1 & 42 & 338 \\
\hline Total & & & & & & & & & & & & & & & & 1652 \\
\hline
\end{tabular}

The average weekly consumer flow is 1652 calculated according to the attendance and repeated utilization of tables and the average monthly consumer flow is $(1652 / 7) \times 30=$ 7080. The consumer flow at breakeven point is 6,000 people, the safe margin $=7080-6000=1080$, rate of safe margin $=$ $1080 / 7080=15.25 \%$.

The safe margin rate of this restaurant is $15.25 \%$, and it is determined that the business safety of $\mathrm{X}$ restaurant business is in a state worthy of attention, having certain operational risk. Based on this, another auxiliary indicator evaluating safety degree can be obtained, namely consumer flow completion rate at breakeven point $=$ consumer flow at breakeven point $/$ average consumer flow $=6000 / 7080=84.75 \%$. In other words, in order to gain profits, the consumer flow must reach more than $84.75 \%$ of the daily measured consumer flow. Obviously, the indicator is of certain guiding significance for the restaurant to strengthen daily business publicity and to make efforts to increase consumer flow.

\section{Analysis of Realization of Enterprise Guaranteed Target Profit}

Under the market economy conditions, no company will take breakeven point as the business objective. But the company will seek development based market supply and demand situation as well as its own condition, as the pursuit of profit is the prerequisite for the company's survival and development. Therefore, the restaurants shall consider the existence of target profits, to fully reveal the relationship among cost, business volume and target profit, namely the CVP relationship under the circumstances that the guaranteed realization of enterprise target profit need to be further analyzed to calculate and measure the company's profitguaranteeing point. Profit-guaranteeing point refers to under the condition that the unit profit and cost level are given, the sales volume and amount of sales need to be reached in order to guarantee the realization of target profit. The profitguaranteeing point of a restaurant can be represented by the profit-guaranteeing consumer flow, with the calculation formula as: profit-guaranteeing consumer flow $=($ target profit + fixed cost) / (unit price - unit variable cost).
It is assumed that the monthly target profit of $\mathrm{X}$ Restaurant is 80,000 yuan, the consumer flow to realize target profit $=$ $(80000+180000) /(70-40)=8667$ (person). If the restaurant wishes to double the target profit to 160,000 yuan, then the consumer flow to realize the target profit $=(160000+180000)$ / $(70-40)=11334$ (person).

It can be seen that if $X$ restaurant's target profit doubled to 160,000 from 80,000 , its profit-guaranteeing consumer flow needs to increase by 2667 people, with the increase rate of $30.77 \%$. In other words, if the restaurant wants to double the target profit, there is no need to double the consumer flow, and it only needs to be upgraded by $30.77 \%$. This is because that the increase in consumer flow only increases the total variable cost, while the total fixed cost will remain unchanged, so the profit can be enhanced significantly.

\section{Analysis of the Degree of Influence on Enterprise Profit by Factor Changes}

While conducting CVP analysis, once one of the factors changes, both the breakeven point and profits will also change. The analysis of the degree of impact on profits by these factors is the so-called sensitivity analysis. In the actual operation, the breakeven point, target sales volume or consumer flow will change along with the constant changes in the price of food raw materials, consumer consumption standard, consumer flow and other factors. Therefore, the restaurants need to determine the degree of influence on profits by various factors by virtue of sensitivity analysis. The sensitive indicator used to reflect the sensitivity degree is the "sensitivity coefficient", and its calculation formula is: Sensitivity Coefficient $=$ Percentage of Profit Change / Factor Change. The purpose of calculating the sensitivity coefficient is to make the restaurant manager clearly understand the importance of sensitivity degree among many other factors, in order to determine the order of influential factors, to take necessary measures and to ensure the realization of target profit.

Take $\mathrm{X}$ restaurant as an example, the monthly profit of this restaurant $=6400 \times(70-40)-180000=12000$ (yuan). Assume each factor increases by $25 \%$ on the basis of this, then the sensitivity of various factors are: 
(1) Sensitivity Coefficient of Monthly Consumer Flow. When monthly consumer flow increases by $25 \%$ : profit $=$ $6400 \times(1+25 \%) \times(70-40)-180000=60000$ (yuan), profit sensitivity $=(60000-12000) / 12000=400 \%$, the Sensitivity Coefficient of consumer flow $=400 \% / 25 \%=16$.

(2) Sensitivity Coefficient of Consumer Consumption Standard. When the consumption standard increases by $25 \%$, the profit $=6400 \times[70 \times(1+25 \%)-40]-180000=124000$ (yuan), profit sensitivity $=(124000-12000) / 12000=933 \%$, sensitivity coefficient of consumption standard $=933 \% / 25 \%=$ 37.32 .

(3) Sensitivity Coefficient of Variable Cost. When variable cost decreases by $25 \%$, profit $=6400 \times[70-40 \times(1-$ $25 \%)]-180000=76000$ (yuan), profit sensitivity $=(76000-$ 12000) $/ 12000=533 \%$, sensitivity coefficient of variable cost $=533 \% /-25 \%=-21.32$.

(4) Sensitivity Coefficient of Fixed Cost. When fixed cost decreases by $25 \%$, profit $=6400 \times(70-40)-180000 \times(1-$ $25 \%)=57000$, profit sensitivity $=(57000-12000) / 12000=$ $375 \%$, sensitivity coefficient of fixed cost $=375 \% /-25 \%=-$ 15.

TABLE IV. ANALYSIS OF SENSITIVITY OF CHANGES IN VARIOUS FACTORS

\begin{tabular}{|l|l|l|l|l|l|}
\hline \multicolumn{1}{|c|}{$\begin{array}{c}\text { Influential } \\
\text { Factor }\end{array}$} & $\begin{array}{c}\text { Degree of } \\
\text { Change }\end{array}$ & $\begin{array}{c}\text { Profit } \\
\text { after } \\
\text { Change }\end{array}$ & $\begin{array}{c}\text { Increases } \\
\text { in Profit }\end{array}$ & $\begin{array}{c}\text { Profit } \\
\text { Increasing } \\
\text { Rate }\end{array}$ & $\begin{array}{c}\text { Sensitivity } \\
\text { Coefficient }\end{array}$ \\
\hline Consumer Flow & $25 \%$ & 60000 & 48000 & $400 \%$ & 16 \\
\hline $\begin{array}{l}\text { Consumer } \\
\text { Consumption } \\
\text { Standard }\end{array}$ & $25 \%$ & 124000 & 112000 & $933 \%$ & 37.72 \\
\hline Variable Cost & $-25 \%$ & 76000 & 64000 & $533 \%$ & -21.32 \\
\hline Fixed Cost & $-25 \%$ & 57000 & 45000 & $375 \%$ & -15 \\
\hline
\end{tabular}

It can be seen from "Table IV" that the sensitivity coefficients of consumer consumption standard and consumer flow are positive numbers, indicating that profit increases or decreases in the same direction of this factor; sensitivity coefficients of unit variable cost and fixed cost are negative, indicating that profit increases or decrease in the opposite direction of this factor. The order of factors affecting $\mathrm{X}$ restaurant's profits can be obtained by putting the above for factors' absolute value from large to small: consumer consumption standard, variable cost, consumer flow and fixed cost.

Consumer consumption standard has the largest sensitivity degree. Therefore, it is the most effective means for $\mathrm{X}$ restaurant to improve consumer consumption standard appropriately to increase its profits. Similarly, the decline in consumption standard is the biggest disadvantage of the restaurant. In addition, the impact on profit by unit variable cost is slightly smaller than that by consumer consumption standard, which also an important sensitive factor. Restaurant manager shall strengthen the management of unit variable cost of the restaurant based on this to bring more profit. In contrast, consumer flow and fixed cost are the less sensitive factors. As a result, $\mathrm{X}$ restaurant shall consider the sensitivity coefficient value of various factors and calculate comprehensively to ensure maximization of profit.

\section{SugGestions On The APPLICATION OF CVP ANALYSIS IN CATERING ENTERPRISES}

\section{A. Reduce Fixed Cost and Variable Cost}

Restaurants can adopt different control methods for different costs.

As for fixed cost control, the absolute amount in an accounting period should be controlled. For instance, after the restaurant has entered into the normal stage of operation, it can reduce the number of senior chefs or other senior staff to reduce the cost of wages. When the restaurant has been operating for a period of time as a franchise restaurant, and enjoys certain status in the local catering industry, it can withdraw from the franchise relationship after balancing the franchise fee and advertising fee to save a lot of fixed costs, and turn to the catering network platform to enhance the reputation.

The consumption level of its unit product shall be controlled for variable cost control. For instance, take all the means to save energy, change over from small pot production to batch production, and reduce the proportion of energy costs in food. The fixed cost of one piece of food item is the same as that of a batch of food, and the food of small weight shall share the same fixed costs, so the pricing coefficient of food with small weight has relatively higher pricing coefficient. The fixed cost shared is equal if batch processing is adopted, and the food pricing coefficient can be reduced. Restaurant managers shall conduct the food and beverage accounting very well, improve the production technology and operational level of food and beverage products, release and use the raw materials in strict accordance with the standards formulated according to product costs, and strive to improve the net rate of raw material, so that one kind of material can be used for multi-purpose and make full use of the leftovers, and reduce the cost of raw material as much as possible.

Restaurant cost accounting involves in raw material procurement, acceptance, storage, custody, material receiving, production, marketing and other links. Restaurant shall establish effective management system for various links, inspect and accept the quality, weight and quantity, supervise and urge the production process, calculate the cost and price carefully, to ensure the accurate accounting of the whole production and operation process. Both the professional financial staff and the professionals of various departments shall not ignore the importance of cost accounting. The full participation method shall be adopted to improve restaurant management level and economic benefits.

\section{B. Ensure Stable Consumer Flow}

With the same site and labor costs, if number of consumers is increased, various resources of the restaurant can be used more efficiently. In the aspect of increasing sales volume and customer purchasing power, the restaurant need to estimate consumer's demand prior to selling, to know about the main ingredients, ingredients, cooking methods and taste, and the 
dish design shall mobilize customer's purchase motivation. Moreover, take the restaurant's interest into account, as the dish with high contribution rate will make customers feel not affordable, yet the dish with low contribution rate will render small profits. [6] If some consumers hesitate to order dishes, the waiter can recommend the high-profit dishes. In general, high-priced dishes and beverages have high gross margin. If these dishes and drinks have good quality and characteristics, the returned consumers will be increased.

\section{Determine the Critical Value of Various Factor to Ensure Profit Realization}

The changes in unit selling price, unit variable costs, sales volume and fixed cost will affect the profits. When reaching to a certain extent, such influence will make the restaurant loss from gaining profits, making the restaurant operation undergone qualitative change. The scope of changes in various factors shall be made clear, namely to determine the critical value of each factor. Restaurant manager can judge the restaurant's risk degree based on these information, so as to take the initiative to find measures to reduce operational risk.

\section{Problems NeEding Attention of CATERING ENTERPRISES IN THE APPLICATION OF CVP ANALYSIS METHOD}

It can be seen from the above examples that the CVP analysis method represents restaurant's profits and losses through some quantitative indicators. The calculation results are more intuitive if the consumer flow is taken as the basic business volume, which is convenient for managers to adjust decisions. However, the CVP analysis method also has some limitations, which shall be noted in the application.

First, limitation of consumer flow predication. The determination of consumer is not as easy as that of the production capacity of industrial enterprises. Consumer flow is subject to the consumer preferences, season and holidays, with the accuracy of its daily estimation results remains to be discussed.

Second, vague cost classification. The costs of some projects are difficult to be accurately divided into fixed cost and variable cost. So the effect of analysis results will be reduced. The unit cost will inevitable fluctuate as the restaurant has all kinds of service items, cuisine and beverages. As a result, error will be bound to be caused in the analysis of predicted data. The existence of error will make the actual economic effect of the decision-making program deviate from the expected value.

Third, the CVP analysis is performed under the condition of unchanged price. The CVP analysis follow the historical cost principle and such information processing procedure will not adapt to the changes in prices, which will hinder the realization of target profit. [7] The restaurant's fixed cost and variable cost is affected by the price change to a large extent, and the selling price of the cuisine will be disturbed by the frequent changes in price, and it is even more than the former. As a result, the original linear breakeven analysis will become a nonlinear breakeven analysis. If the price increase of the cuisine exceeds its cost increase amount, then the lower breakeven point will be obtained. The profit calculated with this method will deviate from the real profit.

\section{CONCLUSION}

The CVP analysis will help the restaurant to find out the real profit growth point using scientific management decision principle, make the scientific operating decision. This paper describes the role of management accounting indicators, such as breakeven point, safety margin, and sensitive coefficient and so on, in the decision-making by virtue of case application. Various resources and structures owned by the restaurants are all changing. So there exist inevitable problems under the condition that only the CVP analysis is applied. Therefore, so the critical amount of profit and loss calculated by formula shall not be considered as the only answer. The error caused by traditional CVP analysis shall be adjusted in a timely manner in combination with the restaurant's condition.

\section{REFERENCES}

[1] Bestech Software. The Breakthrough of Catering Industry Relies on Management and Refinement is the Key to Competition [J]. China Computer \& Communication (Theory), 2015,13:11-12.

[2] Zhang Yixue. On the Application of CVP analysis in Accounting Management in Colleges and Universities [J]. Commercial Accounting, 2014,14:32-34.

[3] Liu Xuefeng, Dong Liancai. Catering Cost Accounting [M]. Beijing: China Light Industry Press, 2013.

[4] Wu Yu. CVP Analysis and Simple Application of It in Newspaper Finance [J]. Friends of Accounting (Mid),2007,01:62.

[5] Hong Hui, Han Haitao, Wang Zhiqi. Establishment of CVP Model of University Digital Library and Empirical Research [J]. Journal of Intelligence, 2009,06:35-38.

[6] Kuang Fenqian. Catering Cost Accounting and Control [M]. Beijing Chemical Industry Press, 2012.

[7] Wu Wanfeng. On the Limitation of CVP Analysis [J]. China Economist, 2007 (5): 155. 